\title{
Job Crafting, Employee Well-being, and Quality of Care
}

Western Journal of Nursing Research

(C) The Author(s) 2016

Reprints and permissions: sagepub.com/journalsPermissions.nav DOI: $10.1177 / 01939459166806 / 4$

wjn.sagepub.com

(S)AGE

\section{Montserrat Yepes-Baldó', Marina Romeo', Kristina Westerberg' ${ }^{2}$, and Maria Nordin ${ }^{2}$}

\begin{abstract}
The main objective is to study the effects of job crafting activities of elder care and nursing home employees on their perceived well-being and quality of care in two European countries, Spain and Sweden. The Job Crafting, the General Health, and the Quality of Care questionnaires were administered to 530 employees. Correlations and hierarchical regression analyses were performed. Results confirm the effects of job crafting on quality of care $\left(r=.29 \mathrm{I}, p<.0 \mathrm{I} ; \beta=.26 \mathrm{I}, p<.0 \mathrm{I} ; \Delta R^{2}=.065, p<.0 \mathrm{I}\right)$ and employees' wellbeing $\left(r=.20 \mathrm{I}, p<.0 \mathrm{I} ; \beta=. \mathrm{I} 7 \mathrm{I}, p<.0 \mathrm{I} ; \Delta R^{2}=.028, p<.0 \mathrm{I}\right)$. A positive linear relationship was found between job crafting and well-being in Spain and Sweden and with quality of care in Spain. On the contrary, in Sweden, the relationship between job crafting and well-being was not linear. Job crafting contributes significantly to employees' and residents' well-being. Management should promote job crafting to co-create meaningful and productive work. Cultural effects are proposed to explain the differences found.
\end{abstract}

\section{Keywords}

employee well-being, nursing home, quality of health care, job crafting

\footnotetext{
'University of Barcelona, Spain

2Umeå universitet, Sweden
}

\section{Corresponding Author:}

Montserrat Yepes-Baldó, Universitat de Barcelona, Passeig Vall d'Hebron, 17I, Barcelona 08035, Spain.

Email:myepes@ub.edu 
In their Policy of Public Health, the European Commission states that one of the greatest social and economic challenges of the 21st century is aging (European Commission, 2016). The European demographic development report (European Commission, 2015) shows an aging population, which means a growing number of elderly persons in need of pensions and care. Voices have been raised to protect and maintain the welfare systems, but there have been budget cuts and even salary cuts for public-sector employees (Greve, 2013). Under these circumstances, elder care and nursing homes have to meet external demands, and deal with their internal structure and processes. When organizations are under pressure, the employees are likely to be affected in various ways, such as their well-being or their ability to give care with high quality standards. It is of concern how elder care and nursing home employees should balance the context demands (i.e., to provide care with high standards of quality) with their well-being.

\section{Job Crafting: Effects on Employees and Their Organizations}

The concept of job crafting (Bakker \& Demerouti, 2007; Wrezesniewski \& Dutton, 2001) was introduced as employees' response to the demands of the workplace. According to these authors, employees are not passive participants but can influence their workplace. Hence, the concept of job crafting focuses on the redesign of the work experience and the processes by which employees change elements of their jobs.

The concept of job crafting includes three dimensions (Wrezesniewski \& Dutton, 2001): (a) the scope or number of tasks the employee develops (for instance, introducing new tasks more suited to employee skills or interests; task crafting), (b) relations with other people and exercising discretion with whom one interacts with at work (for instance, making friends with people with similar skills or interests; relational crafting), and (c) the modification of the meaning of work and social environment (for instance, recognizing the effect on and the importance of the work activity for users, patients, clients, etc.; cognitive crafting).

Wrzesniewski, LoBuglio, Dutton, and Berg (2013), argue that

employees have some degree of latitude in how they craft their jobs. Thus, the potential for job crafting to alter the ways in which employees define the meaning of their work and their work identities is relevant across a broad range of job situations. (p. 282)

The relationship established between job crafting and other variables can be focused on the individual or the organizational level. On the individual level, 
job crafting has been found to have a positive relationship with employees' well-being (Berg, Grant, \& Johnson, 2010; Ghitulescu, 2007; Nielsen \& Abildgaard, 2012; Petrou, Demerouti, \& Breevaart, 2013), work engagement (Brenninkmeijer \& Hekkert-Koning, 2015; Halbesleben, 2011), commitment (Ghitulescu, 2007), and job satisfaction (Wrezesniewski \& Dutton, 2001).

On the organizational level, job crafting facilitates organizational change (Avey, Wernsing, \& Luthans, 2008), enhances performance, and reduces turnover (Ghitulescu, 2007; Leana, Appelbaum, \& Shevchuk, 2009; Petrou et al., 2013; Tims, Bakker, \& Derks, 2015).

These relationships have been studied in different professional groups such as engineers (Ghitulescu, 2007), teachers (Ghitulescu, 2007; Leana et al., 2009), special education teachers (Ghitulescu, 2007), researchers and students (Wellman \& Spreitzer, 2011), salespeople for large consumer products (Lyons, 2008), and nurses (Demerouti, 2014; Müller, Heiden, Herbig, Poppe, \& Angerer, 2016) but not in elderly care settings.

The aim of this research is to investigate the effects of job crafting activities of elder care and nursing home employees on their perceived well-being and quality of care in two European countries, Spain and Sweden. The reason for selecting these two countries is that they represent the north and south of Europe with their similarities and differences. In both countries, the health care sector has experienced significant changes during the years of economic crisis. Although it has been one of the few sectors in which jobs have been created, the working conditions of health workers have worsened: frozen wages, reduction in personnel, work overload, increased staff turnover, decreased status, and reduced work expectations (European Commission, 2012). Nevertheless, the situation in Spain has been particularly severe in terms of the unemployment rate, around 23\% (Instituto Nacional de Estadística, 2016), while in Sweden, the unemployment rate was $7.4 \%$ in 2015 (Statistiska Centralbyrån, 2016).

\section{Method}

\section{Design}

A cross-sectional design was used for this study.

\section{Participants}

A nonprobabilistic accidental sampling was used. We selected two samples of employees (managers and personnel providing direct care to residents), one from Spain and one from Sweden. The inclusion criteria for the study were 
(a) to be employees of the participant organizations, including all positions;

(b) not to be on a leave (sick leave, maternity/paternity, etc.); and (c) to give informed consent to participate in the study. A total of 530 elder care and nursing home employees participated in the present study, 177 from Sweden and 353 from Spain. Overall sample error ( $95 \%$ confidence interval [CI]) was $2 \%$ (1.8\% Spain, 4.4\% Sweden).

\section{Measures}

Job crafting was assessed with the Job Crafting Questionnaire (JCQ). The JCQ scale is a 15-item instrument developed and validated in English by Slemp and Vella-Brodrick (2013). This instrument includes a Cognitive

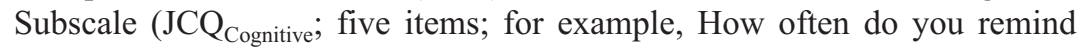
yourself of the importance of your work for the broader community?), a Task Subscale $\left(\mathrm{JCQ}_{\text {Task}}\right.$; five items; for example, How often do you change the scope or types of tasks that you complete at work?), and a Relational Subscale $\left(\mathrm{JCQ}_{\text {Relation }}\right.$; five items; for example, How often do you make friends with people at work who have similar skills or interests?). Participants responded to each item on a 6-point Likert-type scale that ranges from 1 (hardly ever) to 6 (very often). All fit indices supported the three-factor model (nonnormed fit index $[\mathrm{NNFI}]=.95$; incremental fit index $[\mathrm{IFI}]=.96$; comparative fit index $[\mathrm{CFI}]=.96$; root mean square error of approximation $[\mathrm{RMSEA}]=.06,95 \%$ $\mathrm{CI}=[.05, .08])$. The internal consistency of the global scale was .91 (Slemp $\&$ Vella-Brodrick, 2013) and .847 in the present study (Spain $=.851$, Sweden $=.833$ ).

Quality of care was measured by the Quality of Care Questionnaire (QoC). QoC is a five-item instrument developed by Westerberg and Tafvelin (2014) in Swedish. It taps on the elder care and nursing home employees' perceptions about the centrality of care receivers and the attention they receive (e.g., At my workplace, I feel that opinions and wishes of the users/clients receive enough consideration). The internal consistency of the scale was .86 (Westerberg \& Tafvelin, 2014) and .823 in the present study (Spain $=.808$, Sweden $=.824)$.

Psychological well-being was assessed by using the General Health Questionnaire-12 (GHQ-12). GHQ-12 is a one-dimensional 12-item instrument, developed originally by Goldberg (1972). Participants were asked to indicate how often they experience symptoms reflecting their psychological well-being (e.g., In the last four weeks, how often have you felt constantly under strain?) on a 4-point Likert-type scale that ranges from 1 (more than usual) to 4 (much less than usual). Spanish (Rocha, Pérez, Rodríguez-Sanz, Borrell, \& Obiols, 2011) and Swedish (Sconfienza, 1998) versions of the 
instrument were used. The Spanish version has an internal consistency of .86 (Rocha et al., 2011), and the Swedish version, tested in different samples, ranged from .89-.93 (Sconfienza, 1998). In the present study, the internal consistency of this scale was $.870($ Spain $=.836$, Sweden $=.905)$.

In addition, the questionnaire included sociodemographic data related to country (Spain or Sweden), age, gender, and job characteristics, including managerial position and contract (permanent or temporary).

The original scales were adapted to Spanish and Swedish. The objective of the adaptation process was to keep the instrument as near as possible to the original, maintaining the direction of each question and the same structure presented by the authors. Therefore, the guidelines of the International Test Commission (2005) to obtain a linguistically equivalent instrument in Spanish and Swedish were used. First, the translation into Spanish and Swedish was done with the collaboration of three expert consultants in each country, knowledgeable in Spanish or Swedish, and English, and with knowledge of the subject matter and the principles of test development. We have paid special attention to issues such as cultural nuances, colloquial phrases, idiomatic expressions, and cultural differences in the interpretation of many terms. The assessment of the experts ensures terminological accuracy. All discrepancies were cleared up and common versions were derived.

\section{Data Collection Procedure}

Data collection was completed between April and May of 2015. The Swedish participating organizations were recruited at a lecture in a leader training program where the project was presented to managers. Eleven managers decided to participate. Eight municipalities in the north of Sweden and 11 organizations or workplaces are represented.

The questionnaires were distributed in the Swedish organizations by the managers. Each participant also got prepaid envelopes to return their answers to the researchers directly. The response rate was $63.67 \%$ (177/278).

In Spain, four organizations were selected by convenience by the researchers and offered to participate in the project. Four different municipalities in the east of Spain and four organizations or workplaces are represented. The questionnaires were distributed by the researchers, and the employees responded at the workplace where the questionnaires were collected. The response rate was $88.25 \%(353 / 400)$.

In both countries, the study had the approval of the managers and research ethics committees of all participating centers. All participants received a letter explaining the procedure and objectives of the research, ensuring the 
confidentiality of their data and anonymity as well as their right to leave the study at any time without negative consequences for them.

\section{Data Analysis}

Data analysis was performed using SPSS 21. First, we analyzed the differences between countries on sociodemographic data, job characteristics, job crafting, well-being, and quality of care variables by $t$ tests and $\chi^{2}$ comparisons. The data analysis process consisted of three additional steps. First, correlations were sought between the control variables (sociodemographic data and job characteristics), the independent variable (job crafting), and the dependent variables (quality of care and well-being). Fisher's $Z_{\mathrm{r}}$ test (Lipsey \& Wilson, 2001) was used to analyze correlation effect size. Subsequently, hierarchical linear regression analyses were performed. The first step contained a control-only model, including sociodemographic data (gender, age, and country) and job characteristics (position and contract). The second step contained the main analyses, and included the effect of employees' job crafting activities on quality of care and well-being. The assumptions for linear regression analyses were checked by Durbin-Watson Test and standardized residual plots (histogram and normal probability plot). Finally, to analyze graphically the effect of country on job crafting, we recoded the job crafting global scores into three levels based on tertiles (low, medium, and high) as it allows to compare extreme and medium data sets graphically (Der \& Everitt, 2014).

\section{Results}

\section{Sample}

As presented in Table 1, a total of 530 elder care and nursing home employees participated in the present research. The majority of participants were female (87.2\%) and had permanent employment (80\%). A total amount of 55 $(10.4 \%)$ participants reported being managers.

There were some differences between the samples in Sweden and Spain. In Sweden, there was a higher percentage of women $\left(\chi^{2}=4.17, p<.05\right)$. In addition, the percentage of managers in Spain was higher than in Sweden $\left(\chi^{2}=11.3, p<.01\right)$.

\section{Descriptive Statistics}

Overall, the participants reported performing moderate job crafting activities (ranged between 3.02 and 3.24 in a 5-point scale), primarily cognitive job 


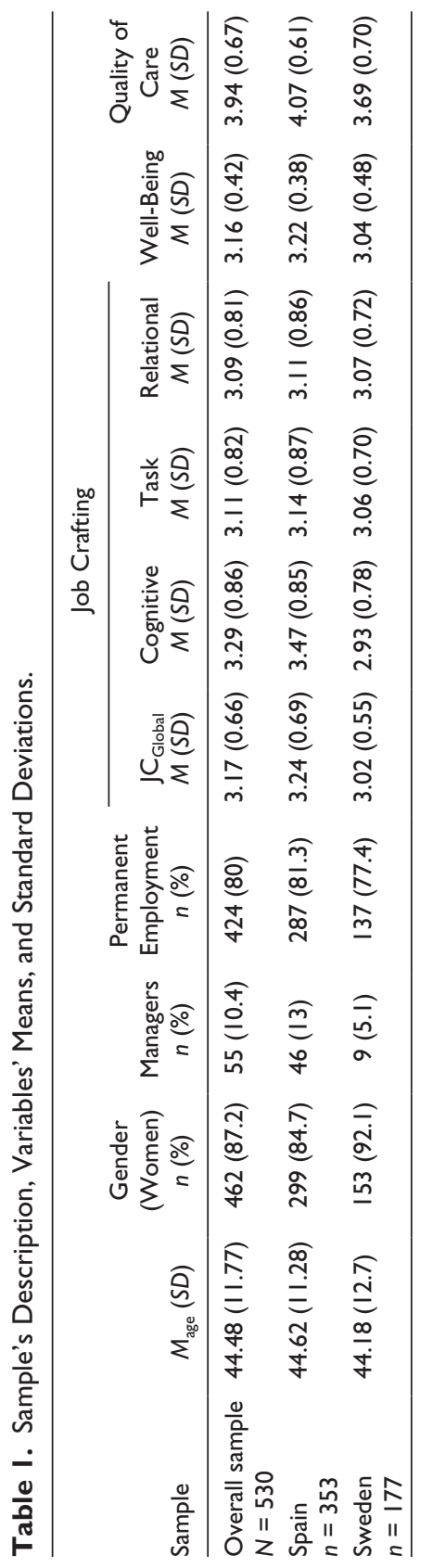


Table 2. Correlations Between Variables.

\begin{tabular}{|c|c|c|c|c|c|c|}
\hline \multirow[b]{2}{*}{ Dimension } & \multirow[b]{2}{*}{ Sample } & \multicolumn{4}{|c|}{ Job Crafting } & \multirow[b]{2}{*}{$\begin{array}{c}\text { Well-Being } \\
r\end{array}$} \\
\hline & & $\underset{r}{J_{\text {Global }}}$ & $\underset{r}{\mathrm{JC}_{\text {Task }}}$ & $\underset{r}{J} C_{\text {Cognitive }}$ & $\begin{array}{c}\mathrm{JC}_{\text {Relation }} \\
r\end{array}$ & \\
\hline \multirow[t]{3}{*}{$\mathrm{JC}_{\text {Task }}$} & Overall sample & $.795^{* *}$ & 一 & & & \\
\hline & Spain & $.813^{* *}$ & & & & \\
\hline & Sweden & $.754 * *$ & & & & \\
\hline \multirow[t]{3}{*}{$J C_{\text {Cognitive }}$} & Overall sample & $.800 * *$ & $.458 * *$ & - & & \\
\hline & Spain & $.812^{* *}$ & $.508 * *$ & & & \\
\hline & Sweden & $.769 * *$ & $.360 * *$ & & & \\
\hline \multirow[t]{3}{*}{$\mathrm{JC}_{\text {Relation }}$} & Overall sample & $.76 I^{* *}$ & $.420 * *$ & $.395^{* *}$ & - & \\
\hline & Spain & $.772 * *$ & $.432 * *$ & $.429 * *$ & & \\
\hline & Sweden & $.755^{* * *}$ & $.385^{* *}$ & $.35 \mathrm{I} * *$ & & \\
\hline \multirow[t]{3}{*}{ Well-being } & Overall sample & $.201 * *$ & $.145 * *$ & $.200 * *$ & $.112 *$ & - \\
\hline & Spain & $.260 * *$ & $.199 * *$ & $.236 * *$ & $.169 * *$ & \\
\hline & Sweden & .021 & .031 & .010 & .004 & \\
\hline \multirow{3}{*}{$\begin{array}{l}\text { Quality of } \\
\text { care }\end{array}$} & Overall sample & $.291 * *$ & $.194 * *$ & $.279 * *$ & $.202 * *$ & $.112^{*}$ \\
\hline & Spain & $.333 * *$ & $.226 * *$ & $.319 * *$ & $.240 * *$ & $.327 * *$ \\
\hline & Sweden & .115 & .117 & .018 & .134 & .37 I** \\
\hline
\end{tabular}

${ }^{*} p<.05 .{ }^{* *} p<.01$.

crafting (ranged between 3.29 and 3.93). They also reported medium $(M=$ 3.69 in a 5-point scale) to high ( $M=4.07$ in a 5-point scale) perception of quality of care and high levels of well-being (ranged between 3.04 and 3.22 in a 4-point scale; Table 1).

There were differences between Spain and Sweden. The Spanish sample reported higher levels in the global measures of job crafting $(t=3.93, p<$ $.01)$, well-being $(t=4.22, p<.01)$, and quality of care $(t=6.23, p<.01)$, and the Cognitive Job Crafting Subscale $(t=7.09, p<.01)$. No differences were found in task and relational job crafting.

Table 2 shows the correlation coefficients between the variables. Job crafting was associated with quality of care and well-being, and quality of care was associated with well-being. Similarly, the job crafting subdimensions correlated with quality of care and well-being. Analyzing by country, the associations between the job crafting, quality of care, and well-being were maintained in the Spanish sample, but in the Swedish sample, there was no association between job crafting and well-being. However, well-being correlated with quality of care in the Swedish sample. Fisher's $Z_{r}$ test ranged between .1125 and .3896 , indicating significant but small effect size. 
Table 3. Regression Analysis of the Relationship Between Employees' Job Crafting and Employees' Well-Being and Quality of Care.

\begin{tabular}{|c|c|c|c|c|c|c|c|c|c|}
\hline \multirow[b]{2}{*}{ Models } & \multicolumn{5}{|c|}{$\begin{array}{l}\text { Control } \\
\text { Variables }\end{array}$} & \multirow{2}{*}{$\begin{array}{c}\begin{array}{c}\text { Independent } \\
\text { Variable }\end{array} \\
\text { Job Crafting } \\
\beta\end{array}$} & \multicolumn{3}{|c|}{$\begin{array}{l}\text { Model } \\
\text { Fit }\end{array}$} \\
\hline & $\begin{array}{c}\text { Country } \\
\beta\end{array}$ & $\begin{array}{c}\text { Gender }^{b} \\
\beta\end{array}$ & $\begin{array}{c}\text { Age } \\
\beta\end{array}$ & $\begin{array}{c}\text { Contract }^{c} \\
\beta\end{array}$ & $\begin{array}{c}\text { Managerial } \\
\text { Position }^{d} \\
\beta\end{array}$ & & $\begin{array}{c}\text { Adjusted } \\
R^{2}\end{array}$ & $\Delta R^{2}$ & $F$ \\
\hline $\begin{array}{c}\text { Controls } \\
\text { only }\end{array}$ & $-.205^{* *}$ & .017 & .058 & .015 & .011 & - & .035 & - & $4.211 * *$ \\
\hline Well-being & $-.177^{* *}$ & .031 & .066 & .01 & .027 & $.17 I^{* * *}$ & .061 & $.028^{* * *}$ & $5.820 * *$ \\
\hline $\begin{array}{l}\text { Controls } \\
\text { only }\end{array}$ & $-.294 * *$ & .014 & .045 & .057 & .018 & - & .082 & - & $8.995 * *$ \\
\hline $\begin{array}{l}\text { Quality of } \\
\text { care }\end{array}$ & $-.254^{* * *}$ & .034 & .056 & .049 & .008 & $.261 * *$ & .146 & $.065^{* * *}$ & 13.772** \\
\hline
\end{tabular}

a. Dummy coded: Spain $=0$, Sweden $=1$.

b. Dummy coded: $0=$ woman, $\mathrm{I}=$ man.

c. Dummy coded: 0 = permanent, $\mathrm{I}=$ temporary.

d. Dummy coded: $0=$ yes, $\mathrm{I}=$ no.

$*_{p}<.05$. **p $<.01$.

\section{Regression Analyses}

Based on correlation results, regression analyses were performed on the association between employees' job crafting and their psychological well-being and quality of care. Durbin-Watson Test $\left(\mathrm{DW}_{\text {well-being }}=1.951 ; \mathrm{DW}_{\text {quality of care }}=\right.$ 1.757) and standardized residual plots (histogram and normal probability plot) indicated the fulfillment of conditions for the linear regression analysis.

The first step included country, gender, age, contract (permanent vs. temporary), and managerial position. The second step included the influence of employees' job crafting on their well-being and quality of care. The controlonly models were statistically significant by country, while the second model was significant in all cases (Table 3 ) and caused a small but significant increment of the $\mathrm{R}^{2}$.

The association between job crafting and quality of care followed the same tendency in both countries but with significantly higher levels in Spain (Figure 1).

On the contrary, the association between job crafting and psychological well-being differed between Spain and Sweden. In Spain, the higher the level of job crafting activities, the higher the psychological well-being level. In contrast, in Sweden, higher and lower levels of job crafting were associated with poorer psychological well-being (Figure 1).

Finally, comparing the levels of psychological well-being in both countries, controlling for level of job crafting activities, we found differences only 


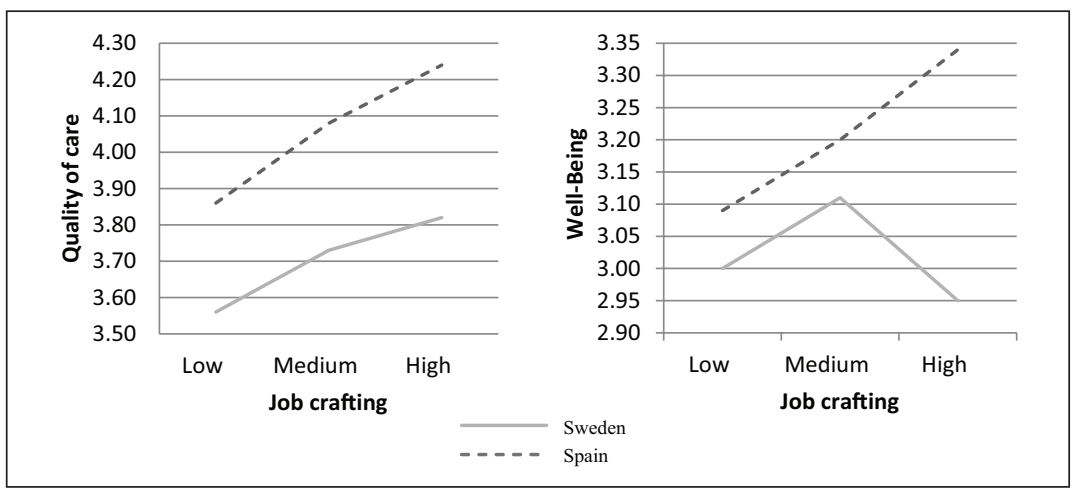

Figure I. Effect of country on the relationship between job crafting, quality of care, and well-being.

on the higher level $(t=-4.78, p<.01)$. For medium and low levels of job crafting, there were no significant differences between Spain and Sweden on well-being.

The three groups also differed somewhat with regard to managerial position. The percentage of managers with high and medium levels of job crafting $(83.7 \%)$ was higher than in employees $\left(64.9 \% ; \chi^{2}=6.215, p<.05\right)$. No differences were found related to gender or contract.

\section{Discussion}

The main objective of the present study was to investigate the effects of job crafting activities of elder care and nursing home employees on their perceived psychological well-being and quality of care in two European countries, Spain and Sweden.

Our results show a positive linear association between job crafting with its subdimensions, psychological well-being and quality of care. Particularly, higher levels of job crafting activities were associated with higher levels of quality of care. When investigating the countries separately, higher levels of job crafting indicated higher levels of psychological well-being in the Spanish sample. However, there was no linear association between these two variables in the Swedish sample. Lower and higher levels of job crafting indicated lower levels of well-being, and medium levels of job crafting indicated the highest level of well-being in the Swedish sample. In addition, the effect of job crafting on well-being and quality of care was significant but small. 
Our results show that the effects of job crafting clearly differ between different contexts. Different authors (Berg, Wrzesniewski, \& Dutton, 2010; Wrzesniewski et al., 2013) have highlighted the importance of context. In this sense, "while context may be seen as a constraint on job crafting, employees' contexts may also provide them with resources to use in crafting their jobs to cultivate positive meaning" (Wrzesniewski et al., 2013, p. 290).

Specifically, analyzing the cultural context and taking into account the cultural model developed by Hofstede (2001), Sweden is included in the Nordic cultural cluster and Spain in the Latin European cluster. Hofstede (2001) conceptualizes Sweden as an individualist society, which means a high preference for a loosely knit social framework in which individuals are expected to take care of themselves. The employer-employee relationship is a contract based on mutual advantage, hiring and promotion decisions are supposed to be based on merit only, and "management is the management of individuals" (Hofstede, 2010, p. 121). This implies that Sweden has a more active job change on its own job design than Spain.

The managers' span of control in Swedish elder care is rather large (Björk, Bejerot, Jacobshagen, \& Härenstam, 2013), which in turn would imply that the staff has to work more independently and take on more responsibilities. In contrast, as can be seen in our results, the span of control in Spain is smaller than in Sweden, with a 13\% of managers (in Sweden, it was 5.1\%). In this sense, job crafting is presumably necessary and successful in the Swedish context, but perhaps other factors related to the span of control, such as high workload, much responsibility, and many organizational changes, level out the effect.

According to European work life comparisons (European Agency for Safety and Health at Work, 2016; Eurofound, 2012), organizational changes and perceived psychosocial risk factors are of considerably higher proportions in Sweden compared with Spain. The inverted U-shape curve shown between job crafting and psychological well-being in the Swedish sample may bear a sign of a third factor, for instance, stress. Another explanation for the Swedish results may be the rather small sample size.

From a practical point of view, it is important to note that job crafting contributes significantly to employees' and residents' well-being. Slemp, Kern, and Vella-Brodrick (2015) point out that managers should incorporate discussions about job crafting into development planning meetings with their staff because it allows employees to take more ownership of their roles or provide training opportunities to teach employees about job crafting to cocreate meaningful and productive work. In this sense, some authors showed examples of healthy and productive job crafting activities such as interacting with different stakeholders not directly related with their task (as medical 
visitor or families; Wrzesniewski, Dutton, \& Debebe, 2003) and paying attention to apparently unimportant information from patients (Wrzesniewski \& Dutton, 2001).

There are some limitations in this study. On one hand, it should be noted that the sample size is relatively small. Future research should include larger samples and add data from other countries. This would entail testing the extent to which the results are applicable across different elder care and nursing home organizations and cultural contexts, and would provide further assurances to its conceptual robustness.

On the other hand, all data have been obtained by the same methodology, which opens up a potential problem of source bias. Future research should include other methods, such as open interviews and observation as well as the application of self-evaluation questionnaires, to avoid the risk of generating spurious correlations through common-method variance (Podsakoff \& Organ, 1986). In addition, objective measures of quality of care should be included to validate the perceptions of employees, as well as other sociodemographic data to be used as control variables.

The study is of cross-sectional design, which makes it impossible to discuss temporal sequence. Job crafting may increase psychological well-being and quality of care. However, feeling well and working in a context where the care is perceived as of high quality also leaves room for job crafting. In this sense, it could be interesting to analyze further whether it is job crafting that provides psychological well-being, or good quality of care, as we found in the present study, or whether it is psychological well-being and good quality of care that allow coworkers to develop their jobs. Thus, longitudinal studies about job crafting in elderly care should be developed in the future.

\section{Declaration of Conflicting Interests}

The author(s) declared no potential conflicts of interest with respect to the research, authorship, and/or publication of this article.

\section{Funding}

The author(s) received no financial support for the research, authorship, and/or publication of this article.

\section{References}

Avey, J. B., Wernsing, T. S., \& Luthans, F. (2008). Can positive employees help positive organizational change? Impact of psychological capital and emotions on relevant attitudes and behaviors. The Journal of Applied Behavioral Science, $44,48-70$. 
Bakker, A., \& Demerouti, E. (2007). The job demands-resources model: State of the art. Journal of Managerial Psychology, 22, 309-328.

Berg, J. M., Grant, A. M., \& Johnson, V. (2010). When callings are callings: Crafting work and leisure in pursuit of unanswered occupational callings. Organization Science, 21, 973-994.

Berg, J. M., Wrzesniewski, A., \& Dutton, J. E. (2010). Perceiving and responding to challenges in job crafting at different ranks: When proactivity requires adaptivity. Journal of Organizational Behavior, 31, 158-186.

Björk, L., Bejerot, E., Jacobshagen, N., \& Härenstam, A. (2013). I shouldn’t have to do this: Illegitimate tasks as a stressor in relation to organizational control and resource deficits. Work \& Stress, 27, 262-277.

Brenninkmeijer, V., \& Hekkert-Koning, M. (2015). To craft or not to craft: The relationships between regulatory focus, job crafting and work outcomes. Career Development International, 20, 147-162.

Demerouti, E. (2014). Design your own job through job crafting. European Psychologist, 4, 237-347.

Der, G., \& Everitt, B. S. (2014). A handbook of statistical graphics using SAS ODS. Boca Raton, FL: CRC Press.

Eurofound. (2012). Fifth European Working Conditions Survey. Luxembourg City, Luxembourg: Publications Office of the European Union. Retrieved from http:// www.eurofound.europa.eu/sites/default/files/ef_publication/field_ef_document/ ef1182en.pdf

European Agency for Safety and Health at Work. (2016). Second European Survey of Enterprises on New and Emerging Risks (ESENER-2). Overview report: Managing safety and health at work. Luxembourg: Publications Office of the European Union. Retrieved from https://osha.europa.eu/sites/default/files/publications/documents/ESENER\%20II\%20-\%20Overview.pdf .

European Commission. (2012). Toward a job-rich recovery. Brussels, Belgium: Author. Retrieved from http://ec.europa.eu/social/main.jsp?catId=89\&;langId=e n\&newsId=1270\&moreDocuments $=$ yes $\&$ tableName $=$ news

European Commission. (2015). The 2015 aging report: Projected demographic changes in the European Union. Retrieved from http://ec.europa.eu/economy_ finance/graphs/2015-05-12_ageing_report_en.htm

European Commission. (2016). Public health ageing. Retrieved from http://ec.europa. eu/health/ageing/policy/index_en.htm

Ghitulescu, B. E. (2007). Shaping tasks and relationships at work: Examining the antecedents and consequences of employee job crafting (Doctoral dissertation). University of Pittsburgh, Pittsburgh, PA.

Goldberg, D. P. (1972). The detection of psychiatric illness by questionnaire: A technique for the identification and assessment of non-psychotic psychiatric illness. Oxford, UK: Oxford University Press.

Greve, B. (2013, June). Is the welfare state dying out? ScienceNordic. Retrieved from http://sciencenordic.com/welfare-state-dying-out 
Halbesleben, J. R. (2011). The consequences of engagement: The good, the bad, and the ugly. European Journal of Work \& Organizational Psychology, 20, 68-73.

Hofstede, G. (2001). Culture consequences: Comparing values, behaviors, institutions, and organizations. Thousand Oaks, CA: Sage.

Hofstede, G. (2010). Cultures and organizations: Software of the mind: Intercultural cooperation and its importance for survival (3rd ed.). New York, NY: McGraw-Hill.

Instituto Nacional de Estadística. (2016). Unemployment rate in Spain. Available from http://www.ine.es/

International Test Commission. (2005). ITC guidelines for translating and adapting tests. Retrieved from http://www.intestcom.org/files/guideline_test_adaptation.pdf

Leana, C., Appelbaum, E., \& Shevchuk, I. (2009). Work process and quality of care in early childhood education: The role of job crafting. Academy of Management Journal, 52, 1169-1192.

Lipsey, M. W., \& Wilson, D. B. (2001). Applied Social Research Methods: Vol. 49. Practical meta-analysis (1st ed.). Thousand Oaks, CA: Sage.

Lyons, P. (2008). The crafting of jobs and individual differences. Journal of Business and Psychology, 23, 25-36.

Müller, A., Heiden, B., Herbig, B., Poppe, F., \& Angerer, P. (2016). Improving wellbeing at work: A randomized controlled intervention based on selection, optimization, and compensation. Journal of Occupational Health Psychology, 21, 169-181.

Nielsen, K., \& Abildgaard, J. S. (2012). The development and validation of a job crafting measure for use with blue-collar workers. Work \& Stress, 26, 365-384.

Petrou, P., Demerouti, E., \& Breevaart, K. (2013). Job crafting as a key to successful organisational change. Gedrag \& Organisatie, 26(1), 32-45.

Podsakoff, P. M., \& Organ, D. W. (1986). Self-reports in organizational research: Problems and prospects. Journal of Management, 12, 531-544.

Rocha, K. B., Pérez, K., Rodríguez-Sanz, M., Borrell, C., \& Obiols, J. (2011). Propiedades psicométricas y valores normativos del General Health Questionnaire (GHQ-12) en población general española [Psychometric properties and normative values of the General Health Questionnaire (GHQ-12) in the Spanish general population]. International Journal of Clinical and Health Psychology, 11(1), 125-139.

Sconfienza, C. (1998). Mätning av psykiskt välbefinnande bland ungdomar i Sverige. Användning av GHQ-12 [Measurement of psychological well-being among young people in Sweden. Use of GHQ 12]. Solna, Sweden: Arbetslivsinstitutet \& författarna.

Slemp, G. R., Kern, M. L., \& Vella-Brodrick, D. A. (2015). Workplace well-being: The role of job crafting and autonomy support. Psychology of Well-Being, 5, Article 7.

Slemp, G. R., \& Vella-Brodrick, D. A. (2013). The Job Crafting Questionnaire: A new scale to measure the extent to which employees engage in job crafting. International Journal of Wellbeing, 3(2), 126-146.

Statistiska Centralbyrån. (2016). Unemployment rate in Sweden. Available from http://www.scb.se/ 
Tims, M., Bakker, A. B., \& Derks, D. (2015). Examining job crafting from an interpersonal perspective: Is employee job crafting related to the well-being of colleagues? Applied Psychology, 64, 727-753.

Wellman, N., \& Spreitzer, G. (2011). Crafting scholarly life: Strategies for creating meaning in academic careers. Journal of Organizational Behavior, 32, 927-931.

Westerberg, K., \& Tafvelin, S. (2014). The importance of leadership style and psychosocial work environment to staff-assessed quality of care: Implications for home help services. Health and Social Care in the Community, 22, 461-468.

Wrezesniewski, A., \& Dutton, J. E. (2001). Crafting a job: Revisioning employees as active crafters of their job. Academy of Management Review, 26, 85-103.

Wrzesniewski, A., Dutton, J. E., \& Debebe, G. (2003). Interpersonal sensemaking and the meaning of work. Research in Organizational Behavior, 25, 93-135.

Wrzesniewski, A., LoBuglio, N., Dutton, J. E., \& Berg, J. M. (2013). Job crafting and cultivating positive meaning and identity in work. Advances in Positive Organizational Psychology, 1(1), 281-302. 